\title{
A process for purifying xylosugars of pre-hydrolysis liquor from kraft-based dissolving pulp production process
}

\author{
Jiachuan Chen ${ }^{1}$, Jiran Dong ${ }^{1}$, Guihua Yang ${ }^{1 *}$, Ming He${ }^{1}$, Feng $\mathrm{Xu}^{1}$ and Pedram Fatehi ${ }^{1,2}$
}

\begin{abstract}
Background: In the kraft-based dissolving pulp production process, pre-hydrolysis liquor (PHL) is produced, which contains hemicelluloses, lignin, furfural and acetic acid. PHL is currently burned in the recovery boiler of the kraft pulping process, but it can be utilized for the generation of high-valued products, such as xylitol and xylanase, via fermentation processes. However, some PHL constituents, e.g., furfural and lignin, are contaminants for fermentation processes and they must be eliminated for production of value-added products.

Results: In this work, a process is introduced for removing contaminants of PHL. $\mathrm{Ca}(\mathrm{OH})_{2}$ treatment is the first step of this process, which removed $41.2 \%$ of lignin and negligible amount of sugars. In this step, a notable increase in the concentration of acetic acid was achieved (ranging from 6.2 to $11.7 \mathrm{~g} / \mathrm{L}$ ). In the second step, the implementation of adsorption using activated carbon (AC) at $1 \mathrm{wt} \%$ dosage led to additional 32\% lignin and 5.9\% xylosugar removals. In addition, laccase assisted activated carbon treatment led to further removal of lignin via accelerating lignin polymerization and adsorption on AC (i.e., removal from PHL). Overall, $90.7 \%$ of lignin, 100\% of furfural, $5.7 \%$ of xylose, and 12\% of xylan were removed from PHL, while the concentration of acetic acid became twofolds in the PHL.

Conclusions: This study reports an attractive process for purifying sugars and acetic acid of PHL. This process may be implemented for producing sugar-based value-added products from PHL. It also discusses the mechanism of $\mathrm{Ca}(\mathrm{OH})_{2}$ treatment, AC adsorption and laccase assisted activated carbon treatment for lignin removal.
\end{abstract}

Keywords: Pre-hydrolysis liquor, $\mathrm{Ca}(\mathrm{OH})_{2}$, Lignin removal, Activated carbon, Laccase, Xylosugars

\section{Background}

In the hydrolysis stage of kraft-based dissolving pulp process, most of the hemicellulose and part of lignin are dissolved into liquor that is called pre-hydrolysis liquor (PHL). Currently, PHL is considered a waste liquor and mixed with black liquor for combustion in the recovery boiler of the kraft process $[1,2]$. However, because of its dilute nature and its low heating value, its combustion is unprofitable [3].

Previous studies showed that the PHL from the kraftbased dissolving pulp production process generally

\footnotetext{
*Correspondence: ygh2626@126.com

1 State Key Laboratory of Bio-based Materials and Green Papermaking, Qilu University of Technology (Shandong Academy of Sciences), Jinan 250353, Shandong, China

Full list of author information is available at the end of the article
}

contains 3-5\% organics, which can be converted to value-added products, such as ethanol and xylitol [4]. Moreover, hemicellulose, e.g., xylose, is widely used in the food and medicine industries owing to its ulcer protection [5], antitussive [6] and immunostimulatory [7] effects. However, the presence of lignin in the PHL hinders the utilization of hemicelluloses. For example, lignin hinders sugar fermentation to produce ethanol or xylitol [8]. Therefore, finding an effective approach to eliminate contaminants is crucial for generating hemicellulosebased value-added products from PHL.

In the past, solvent extraction was employed to separate/isolate hemicellulose from PHL [9]. Despite its high efficiency, the complexity of solvent recovery, the high operational costs and technical issues constrained the commercialization of this technology [1]. 
Acidification has also been proposed to isolate lignin from PHL, but its effectiveness was defective [10]. Other methods were also studied for purifying pentoses from PHL including (i) physical treatments, such as membrane extraction and activated carbon (AC) treatment [1,11]; (ii) chemical treatments, such as poly dimethyl diallyl ammonium chloride (PDADMAC) treatment; and (iii) biochemical treatments, such as laccase treatment [12]. Membrane extraction is effective, but it has a major filter blockage and is costly to operate [13]. PDADMAC is poor in removing lignin, it is an expensive chemical and it may cause environmental issues [14]. Therefore, a more effective method should be developed for removing/isolating contaminants from PHL for facilitating hemicellulose usage.

In one study, lime treatment was an effective approach for removing lignin from PHL, but an extensive sugar degradation was reported at a high dosage of lime in PHL [15]. Lime treatment may be an acceptable option if it is used at a low dosage, as it is well in harmony and is actually used in the kraft-based pulping process. Therefore, the first objective of this work is to study whether $\mathrm{Ca}(\mathrm{OH})_{2}$ treatment can benefit the utilization of hemicelluloses of PHL.

Activated carbon (AC) has been vastly used as an adsorbent in industry [16]. It is a widely available and effective material for adsorption of lignin [17]. However, AC adsorbs both lignin and hemicelluloses [1]. In the past, $\mathrm{AC}$ was used to adsorb lignin and sugar from a mixed solution [3]. Lignin is hydrophobic, but sugars are hydrophilic, therefore, the adsorption of these chemicals on AC may be poor. The second objective of this work was to investigate if $\mathrm{AC}$ addition can be combined with other methods to increase its selectivity towards adsorbing PHL contaminants.

Recently, laccase, a copper-containing oxidase, has received attention for its sustainable selectivity for lignin removal under mild reaction conditions. It is known that laccase treatment can increase lignin's molecular weight [18]. This is attributed to the fact that laccase can polymerize small lignin molecules to make them more hydrophobic, which can enhance lignin removal from PHL $[1,12]$. The third objective of this work is to investigate the effect of laccase treatment on lignin removal from PHL.

In the past, some process operations were suggested for removing lignin from PHL, but these processes had limited removal efficiencies $[1,15,18]$. The main novelty of this work is the design of an attractive process via combining single state processes for efficiently separating contaminants from PHL, while maintaining xylosugars and acetic acid in the PHL for their possible utilization in downstream biochemical or chemical processes.

\section{Methods \\ Materials}

Industrially produced pre-hydrolysis liquor (PHL) was collected from a kraft-based dissolving pulp mill located in eastern China. Eucalyptus wood chips were used as raw materials. The pre-hydrolysis was performed at $170{ }^{\circ} \mathrm{C}$ for $60 \mathrm{~min}$ as it practiced at the mill. The chemical constituents of PHL are listed in Table $1 . \mathrm{Ca}(\mathrm{OH})_{2}$ (particle size $5 \mu \mathrm{m}$ ), $\mathrm{H}_{2} \mathrm{SO}_{4}$, dioxane, ethyl ether, pyridine, acetic anhydride, tetrahydrofuran (THF) and $\mathrm{P}_{2} \mathrm{O}_{5}$ were all analytical grades and purchased from Tianjin Hengxing Company. Activated carbon was obtained from Guangzhou Haiyan Company. Laccase and 2, 2'-azino-bis (3-ethylbenzthiazoline-6-sulfonate) (ABTS) were purchased from Sigma-Aldrich. Laccase activity was determined by using a UV-vis spectrophotometer (Agilent Technologies, Palo Alto, America) at $420 \mathrm{~nm}$ and pH 4.5 at $20^{\circ} \mathrm{C}$ with $0.5 \mathrm{mM}$ ABTS as the substrate, as described by Mansfield [19]. One activity unit (U/ $\mathrm{mL}$ ) was defined as the amount of enzyme that oxidized $1 \mu \mathrm{mol}$ of ABTS in a minute.

Figure 1 shows the flow chart of the experimental procedure to purify xylosugars of the PHL. As seen in Fig. 1, PHL was collected from hot water hydrolysis process and the hydrolyzed wood chips were subsequently used to produce dissolving pulp. PHL was treated by $\mathrm{Ca}(\mathrm{OH})_{2}$, $\mathrm{AC}$ and laccase assisted $\mathrm{AC}$ for removing contaminants from PHL (i.e., purifying xylosugars in PHL).

Table 1 Chemical constituents of original PHL

\begin{tabular}{lcllll}
\hline Monomeric form (g/L) & \multicolumn{3}{l}{ Oligomeric form $\mathbf{( g / L )}$} & & \multicolumn{2}{l}{ Other products (g/L) } \\
\hline Xylose & $12.3 \pm 0.68$ & Xylose & $23.3 \pm 0.79$ & Soluble lignin & $9.7 \pm 0.49$ \\
Arabinose & $0.2 \pm 0.005$ & Arabinose & $0.1 \pm 0.006$ & Acetic acid & $6.2 \pm 0.26$ \\
Galactose & $0.4 \pm 0.013$ & Galactose & $1.4 \pm 0.067$ & Furfural & $1.9 \pm 0.1$ \\
Glucose & $0.4 \pm 0.017$ & Glucose & $1.2 \pm 0.055$ & HMF & $0.4 \pm 0.032$ \\
Mannose & $0.3 \pm 0.006$ & Mannose & $1.0 \pm 0.03$ & & $18.2 \pm 0.453$ \\
Total & $13.6 \pm 0.721$ & Total & $27.0 \pm 0.948$ & Total & \\
\hline
\end{tabular}

HMF hydroxymethylfurfural 


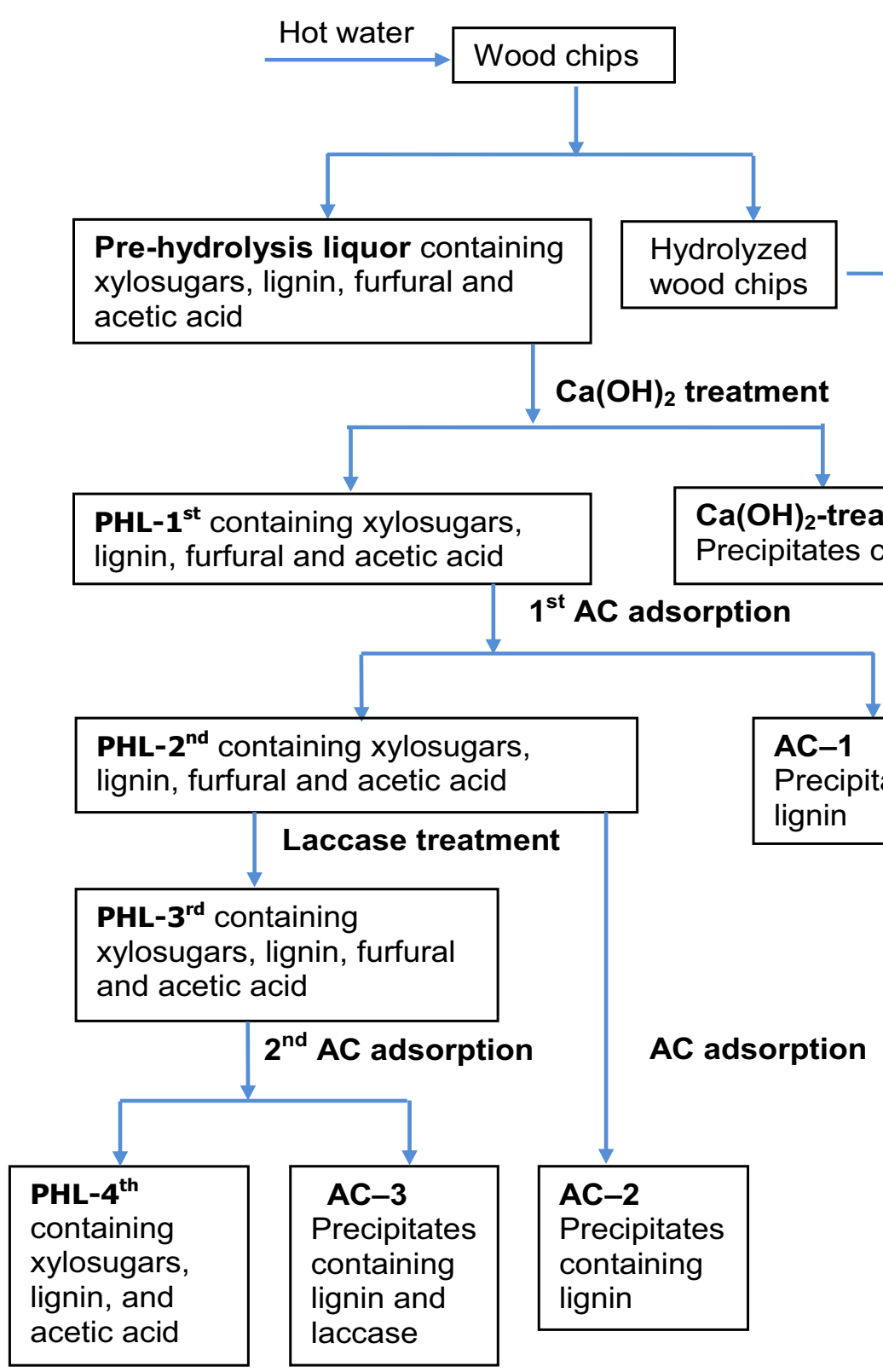

Fig. 1 Experimental procedure for removing contaminants and purifying xylosugars

$\mathrm{Ca}(\mathrm{OH})_{2}$ treatment of $\mathrm{PHL}$

$\mathrm{Ca}(\mathrm{OH})_{2}$ treatment experiments was conducted at $25{ }^{\circ} \mathrm{C}$. Different amounts $(0.5-4.0 \mathrm{~g})$ of $\mathrm{Ca}(\mathrm{OH})_{2}$ were added into glass flasks containing $100 \mathrm{~g}$ of PHL. The mixtures were stirred at $250 \mathrm{rpm}$ for $5 \mathrm{~min}$ at room temperature. These conditions were selected according to literature results and process optimization (not shown) [15]. The treated liquors were centrifuged at $4500 \mathrm{rpm}$ for $3 \mathrm{~min}$. The precipitates (containing calcium hydroxide particles) were collected for Fourier transform infrared spectroscopy (FT-IR) analysis. The first filtrates of PHL were neutralized to $\mathrm{pH} 7$ by using $\mathrm{H}_{2} \mathrm{SO}_{4}$ for forming precipitates of $\mathrm{CaSO}_{4}$ and then were centrifuged to obtain the filtrates of $\mathrm{PHL}$, which were denoted as PHL-1st (Fig. 1). Each experiment was repeated three times to ensure the experimental repeatability. The error bars show the variations in the experimental results.

\section{1st $A C$ adsorption stage}

The adsorption experiments were performed at $25{ }^{\circ} \mathrm{C}$ with adding different dosages of activated carbon 
(0.5 wt\%, $1.0 \mathrm{wt} \%, 2.0 \mathrm{wt} \%, 4.0 \mathrm{wt} \%$ and $6.0 \mathrm{wt} \%)$ to $100 \mathrm{~g}$ of PHL-1st in glass flasks. The agitation was performed at $150 \mathrm{rpm}$ for $5 \mathrm{~min}$ (Fig. 1). Then, the samples were filtered using regular filter papers. The filtrates of this process were collected as PHL-2nd. The precipitates were collected as AC-1. It should be stated that the adsorption of PHL components on the filter papers used in this study was tested, and the results confirmed negligible removals. Therefore, filtration had minimal impact on the removal of PHL components.

\section{Laccase assisted AC treatment Laccase treatment}

Laccase treatment experiments were carried out in Erlenmeyer flasks at $150 \mathrm{rpm}$ of shaking rate and different treating conditions. The dosages of laccase varied from 0 to $10 \mathrm{U} / \mathrm{g}$ in $30 \mathrm{~g}$ of PHL-2nd. The $\mathrm{pH}$ of this treatment ranged from 4 to 8 . The treating temperature and time were $25-55^{\circ} \mathrm{C}$ and $1-5 \mathrm{~h}$, respectively. In this test, the mixture was boiled for $10 \mathrm{~min}$ to deactivate laccase after laccase treatment. The mixtures were collected as PHL-3rd. The effect of laccase treatment on the average molecular weight $(\mathrm{Mw})$ and number-average molecular weight (Mn) of lignin of the PHL before (for PHL-2nd) and after (for PHL-3rd) this treatment was evaluated.

\section{2nd AC adsorption stage}

The PHL-3rd obtained under the optimal laccase treatment conditions was mixed with $0.2 \mathrm{wt} \%$ to $1.2 \mathrm{wt} \%$ of $\mathrm{AC}$. The other conditions of this $\mathrm{AC}$ adsorption stage were same as those of the first AC adsorption stage. After the treatment, the mixtures were filtered using filter papers and the collected filtrate was denoted as PHL-4th. The collected treated AC was denoted as AC-3 and its surface area and pore structure were analyzed.

To understand the influence of laccase treatment on the contaminant removal, $1 \mathrm{wt} \%$ of $\mathrm{AC}$ was added into PHL-2nd, and the treated AC of this step was denoted as AC-2 after collection. The other experimental conditions in this step were the same as those followed for producing $\mathrm{AC}-3$, but without the laccase treatment.

\section{Chemical component analysis}

The monosaccharide concentrations in PHL were determined by an ion chromatography (ICS-5000+, Thermo Scientific, America), which was equipped with a Dionex CarboPac PA20 column $(3 \mathrm{~mm} \times 150 \mathrm{~mm}$, Thermo Scientific, America) and an ED40 electrochemical detector. Samples were run at $30{ }^{\circ} \mathrm{C}$ and the flow rate was $0.4 \mathrm{~mL} /$ min in this instrument. The mobile phase used in the chromatography consisted of $4 \%$ of $50 \mathrm{mmol} / \mathrm{L} \mathrm{NaOH}$ and $96 \%$ of ultrapure water for a period of $22 \mathrm{~min}$. Then, the eluent was switched to $40 \%$ of $1 \mathrm{~mol} / \mathrm{L} \mathrm{NaCOOCH}$, $20 \%$ of ultrapure water and $40 \%$ of $50 \mathrm{mmol} / \mathrm{L} \mathrm{NaOH}$ for another $5 \mathrm{~min}$; and it was finally switched to $20 \%$ of ultrapure water and $80 \%$ of $250 \mathrm{mmol} / \mathrm{L} \mathrm{NaOH}$ for another 28-35 min. For measuring the concentration of oligosaccharides in solutions, an additional acid hydrolysis step was carried out on the collected samples under the conditions of $4 \%$ sulfuric acid concentrations at $121{ }^{\circ} \mathrm{C}$ for $1 \mathrm{~h}$ in an oil bath. Then, the concentrations of sugars in the acidified samples were determined following the method stated above. The concentration of oligosaccharides was determined via subtracting the concentration of monosaccharides before this acid hydrolysis step from that obtained after the acid hydrolysis stage.

The concentrations of acetic acid, furfural and hydroxymethylfurfural (HMF) in the solutions were measured by a Shimadzu LC-20T high performance liquid chromatography (HPLC) system (Japan), which was equipped with a SUPELCOGEL C-610H column $(30 \mathrm{~cm} \times 7.8 \mathrm{~mm}$, Sigma-Aldrich, America) and a SPD-20A detector. Samples were run at $30{ }^{\circ} \mathrm{C}$ and eluted at $0.7 \mathrm{~mL} / \mathrm{min}$, and mobile phase was $0.1 \% \mathrm{H}_{3} \mathrm{PO}_{4}$. The samples were filtered using a $0.22 \mu \mathrm{m}$ Nylon syringe filter prior to the analysis.

The concentration of lignin in solutions was determined by a UV/vis spectrophotometer (Agilent Technologies, Palo Alto, America) according to the TAPPI standard TAPPI UM 250 method at wavelength of $205 \mathrm{~nm}$ [20].

\section{Particle size analyses}

The particle size of the components in PHL was measured by a particle size analyzer, Malvern Zetasizer Nano ZSP (Malvern, UK). The scattering angle and operating wavelength were $90^{\circ}$ and $658 \mathrm{~nm}$, respectively. The mean diffusion coefficient was obtained using a dynamic light scattering (DLS) (Malvern, UK) measurement. The hydrodynamic sizes of the components in PHL were calculated following Stokes-Einstein Equation [21]. The sample was diluted 50 times and filtered using $0.22 \mu \mathrm{m}$ nylon filters before the measurement.

\section{Lignin isolation}

The lignin of the PHL untreated and treated by laccase was isolated by following the method described in the literature [22]. The PHL was acidified to $\mathrm{pH} 2$ by $\mathrm{H}_{2} \mathrm{SO}_{4}$, and its lignin was precipitated and separated by centrifugation at $5000 \mathrm{rpm}$. The precipitated lignin sample was thoroughly washed with distilled water to neutrality. Then, the lignin obtained after washing was dissolved in dioxane $(9 / 1 \mathrm{vol} / \mathrm{vol})$ and precipitated in ether under constant stirring. The precipitated lignin was dried in vacuum over $\mathrm{P}_{2} \mathrm{O}_{5}$. 


\section{Acetylation and gel permeation chromatography}

The lignin samples obtained previously (200 $\mathrm{mg}$ ) were acetyl-brominated in a mixture of $10 \mathrm{~mL}$ of dry pyridine/acetic anhydride $(1 / 2 \mathrm{vol} / \mathrm{vol})$ and kept in the dark for $72 \mathrm{~h}$ (room temperature, $25^{\circ} \mathrm{C}$ ). Once the bromination was complete, the solutions were added to a tenfold volume of ethyl ether. The mixture was centrifuged, and the acetylated lignin was recovered as precipitates. Subsequently, the precipitates were purified by successive washing with ethyl ether and dried under vacuum over $\mathrm{P}_{2} \mathrm{O}_{5}$. The purified lignin was dissolved in tetrahydrofuran (THF). Then, the weight average (Mw) and number average molecular $(\mathrm{Mn})$ weights of acetylated lignin were determined by a gel permeation chromatography (GPC) using a Shodex KF-802.5 column with UV detection $(280 \mathrm{~nm})$ and differential refractive index (RI) detection. The analyses were carried out at $30^{\circ} \mathrm{C}$ using THF as the eluent at the flow rate of $1 \mathrm{~mL} / \mathrm{min}$.

\section{Characterization of $\mathrm{Ca}(\mathrm{OH})_{2}$ and activated carbon}

The surface functional groups of $\mathrm{Ca}(\mathrm{OH})_{2}$ and $\mathrm{AC}$ before and after treatment were characterized by using a Fourier transform infrared spectrometer (VERTEX70, Bruker, Germany). The oven-dried samples were embedded in $\mathrm{KBr}$ pellets in a mixture of about $1 \mathrm{wt} \% \mathrm{KBr}$. The spectra were monitored in a transmittance band mode in the range $500-2500 \mathrm{~cm}^{-1}$.

The BET surface area and pore structure characteristics of original $\mathrm{AC}, \mathrm{AC}-2$ and $\mathrm{AC}-3$ were determined by using a surface area analyzer (v-sorb2800p, Gold APP Instrument Corporation, Beijing, China) via nitrogen adsorption/desorption isotherms. About $0.1 \mathrm{~g}$ of $\mathrm{AC}$ was pretreated at $110{ }^{\circ} \mathrm{C}$ overnight for contamination removal. Afterward, the measurement was carried out using nitrogen as a probe at $77 \mathrm{~K}$ overnight.

\section{High heating values (HHV) analysis}

Organic elements $(\mathrm{C}, \mathrm{H}, \mathrm{O}, \mathrm{N}$ and $\mathrm{S})$ of $\mathrm{AC}$ before and after treatment were estimated by using a Vario EL III Elementar (USA). About $2.5 \mathrm{mg}$ of sample was pretreated at $105{ }^{\circ} \mathrm{C}$ overnight for moisture removal. High heating value (HHV) was calculated following Eq. 1 [23].

$$
\begin{aligned}
\operatorname{HHV}(\mathrm{MJ} / \mathrm{kg})= & 0.3491 \mathrm{C}+1.1783 \mathrm{H}+0.1005 \mathrm{~S} \\
& -0.1034 \mathrm{O}-0.0151 \mathrm{~N}-0.021 \mathrm{~A}
\end{aligned}
$$

where, $\mathrm{C}, \mathrm{H}, \mathrm{S}, \mathrm{O}, \mathrm{N}$, and A represent carbon, hydrogen, sulfur, oxygen, nitrogen, and ash content (wt\%) of the samples, respectively.

\section{Results and discussion}

\section{Chemical analysis of original PHL}

The chemical constituents of the original PHL are shown in Table 1. It can be seen that xylosugars were the
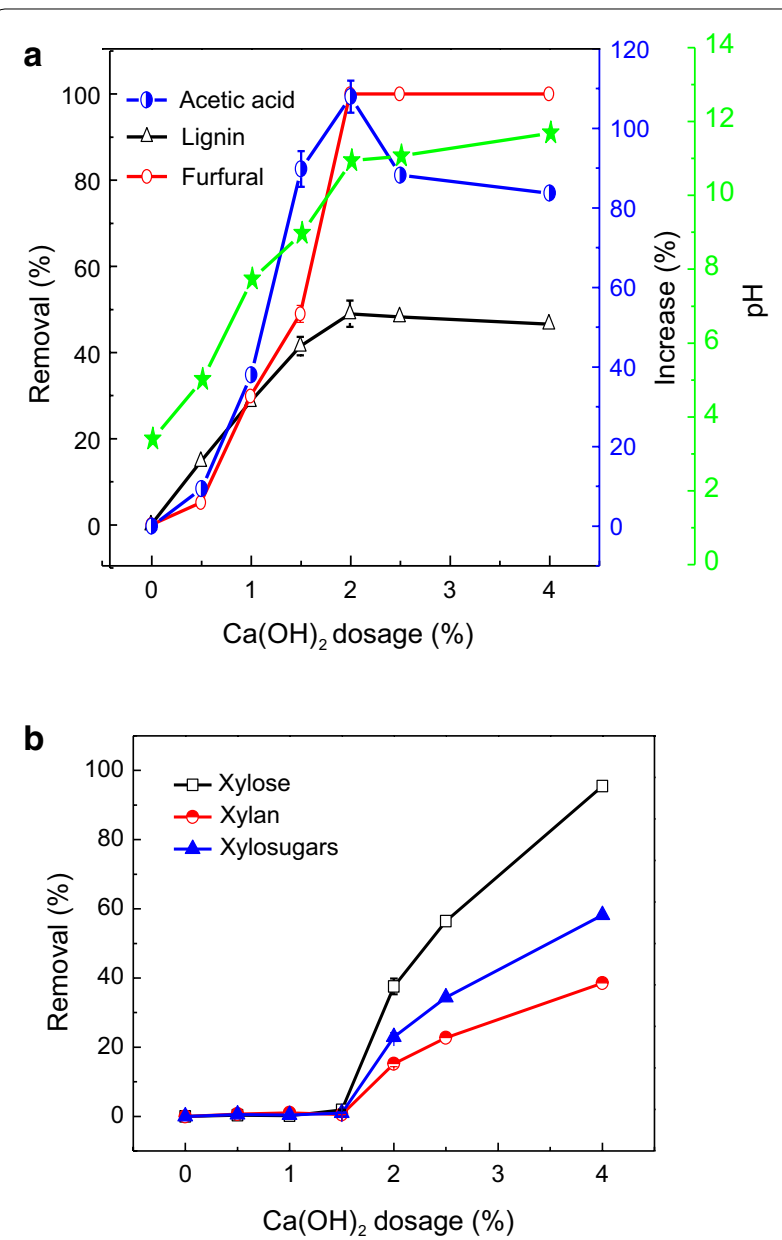

Fig. 2 Effect of $\mathrm{Ca}(\mathrm{OH})_{2}$ dosage on the constituents of original $\mathrm{PHL}$ (a removal of lignin and furfural, and increase of acetic acid; $\mathbf{b}$ removal of xylose, xylan and xylosugars)

primary components of PHL as hardwood was used in the dissolving pulp production process, and these findings are similar to those reported earlier [3, 24].

\section{$\mathrm{Ca}(\mathrm{OH})_{2}$ treatment}

The effect of $\mathrm{Ca}(\mathrm{OH})_{2}$ dosage on the removal of acetic acid, lignin and furfural in PHL is shown in Fig. 2a. The $\mathrm{pH}$ of the PHL increased rapidly with increasing $\mathrm{Ca}(\mathrm{OH})_{2}$ dosage. However, the $\mathrm{pH}$ was changed negligibly when $\mathrm{Ca}(\mathrm{OH})_{2}$ dosage was more than $2 \mathrm{wt} \%$, which was most probably due to the limited solubility of the $\mathrm{Ca}(\mathrm{OH})_{2}$ in PHL. The removal of lignin increased by about $50 \%$ when $\mathrm{Ca}(\mathrm{OH})_{2}$ dosage was increased to $2 \%$. It was reported that calcium could generate complexes with lignin, which implied that the complexation between lignin of PHL and dissolved calcium ions might have contributed to the removal of lignin [15]. In addition, the adsorption of lignin onto the $\mathrm{Ca}(\mathrm{OH})_{2}$ particles might have contributed to the lignin removal from PHL $[3,15]$. 
The removal of furfural increased by $49 \%$ at $1.5 \mathrm{wt} \%$ of $\mathrm{Ca}(\mathrm{OH})_{2}$ in PHL. Furfural in the PHL was all removed with further increasing $\mathrm{Ca}(\mathrm{OH})_{2}$ dosage. The reason might be that furfural was oxidized under alkaline conditions. On the other hand, with increasing $\mathrm{Ca}(\mathrm{OH})_{2}$ dosage from 0 to $2 \mathrm{wt} \%$, the acetic acid concentration increased from 6.2 to $12.9 \mathrm{~g} / \mathrm{L}$, which was due to the cleavage of acetyl groups of hemicellulose dissolved in PHL [15]. A further increase in $\mathrm{Ca}(\mathrm{OH})_{2}$ dosage decreased the acetic acid concentration slightly. This change was presumably due to the adsorption of acetic acid onto calcium hydroxide particles as reported earlier $[3,15]$.

Interestingly, the increase in $\mathrm{Ca}(\mathrm{OH})_{2}$ dosage to more than $2 \mathrm{wt} \%$ did not improve the removal of organics from PHL, which implied that the $\mathrm{pH}$ change of PHL and complexation between the PHL constituents and the dissolved $\mathrm{Ca}(\mathrm{OH})_{2}$ played more important roles than physical adsorption of organic materials on undissolved calcium oxide.

$\mathrm{Ca}(\mathrm{OH})_{2}$ treatment had a negligible effect on xylosugar removal when the $\mathrm{Ca}(\mathrm{OH})_{2}$ dosage was below $1.5 \mathrm{wt} \%$ (Fig. 2b). However, with further increase of $\mathrm{Ca}(\mathrm{OH})_{2}$ dosage from 1.5 to $4 \mathrm{wt} \%$, the removal of xylosugar was significantly increased from 1 to $58 \%$. One of reasons for this phenomenon was attributed to the hydroxide-catalyzed degradation reactions of xylosugars [25], and another reason might be the adsorption of xylosugars onto the calcium hydroxide particles, especially at a high $\mathrm{Ca}(\mathrm{OH})_{2}$ dosage [15]. Therefore, for the purpose of removing lignin with minimum loss of xylosugars, the optimal dosage of $1.5 \mathrm{wt} \% \mathrm{Ca}(\mathrm{OH})_{2}$ was selected for further analysis.

The functional groups of the treated and untreated $\mathrm{Ca}(\mathrm{OH})_{2}$ were analyzed by the FTIR (Fig. 3). Several peaks appeared on the spectrum of $\mathrm{Ca}(\mathrm{OH})_{2}$. Peaks at

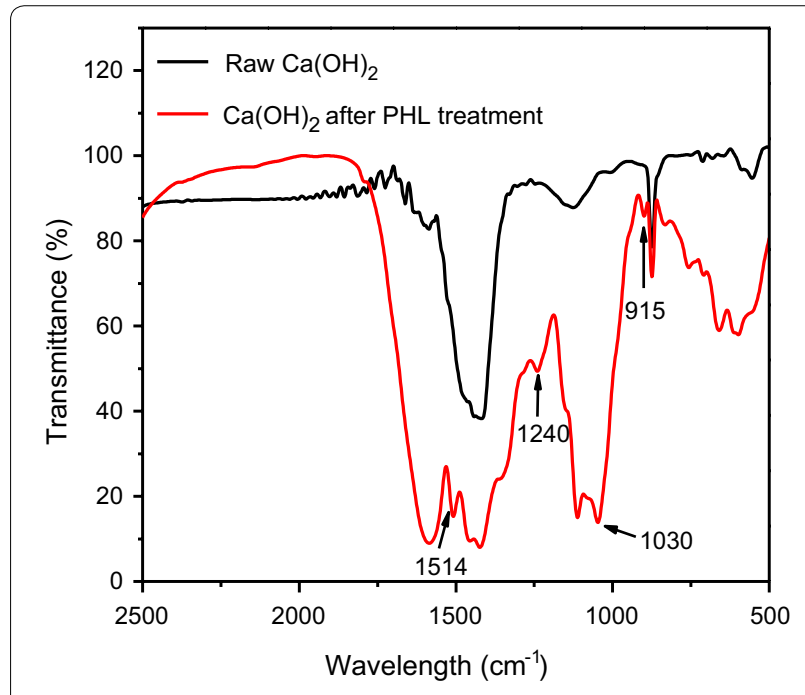

Fig. 3 FTIR spectrum of the treated and untreated $\mathrm{Ca}(\mathrm{OH})_{2}$
1514 and $915 \mathrm{~cm}^{-1}$ could be ascribed to the vibration of the aromatic skeletal and the $\mathrm{C}-\mathrm{H}$ bending of aromatic nucleus, respectively [26]. The peaks at $1460 \mathrm{~cm}^{-1}$ could be attributed to the deformation of $\mathrm{C}-\mathrm{H}$ (methyl and methylene) [27]. In addition, the peaks at 1240 and $1030 \mathrm{~cm}^{-1}$ could be assigned to the $\mathrm{C}-\mathrm{H}$ and $\mathrm{C}-\mathrm{O}$ bending of guaiacyl ring [28]. It was confirmed from FTIR spectrum that a portion of lignin and lignin-derivatives were adsorbed on $\mathrm{Ca}(\mathrm{OH})_{2}$ particles in the process of $\mathrm{Ca}(\mathrm{OH})_{2}$ treatment.

\section{1 st $\mathrm{AC}$ adsorption}

The PHL-1st (i.e., PHL of the $\mathrm{Ca}(\mathrm{OH})_{2}$ treatment) was treated with $\mathrm{AC}$ for removing contaminants from PHL and the results are shown in Fig. 4. It can be seen from
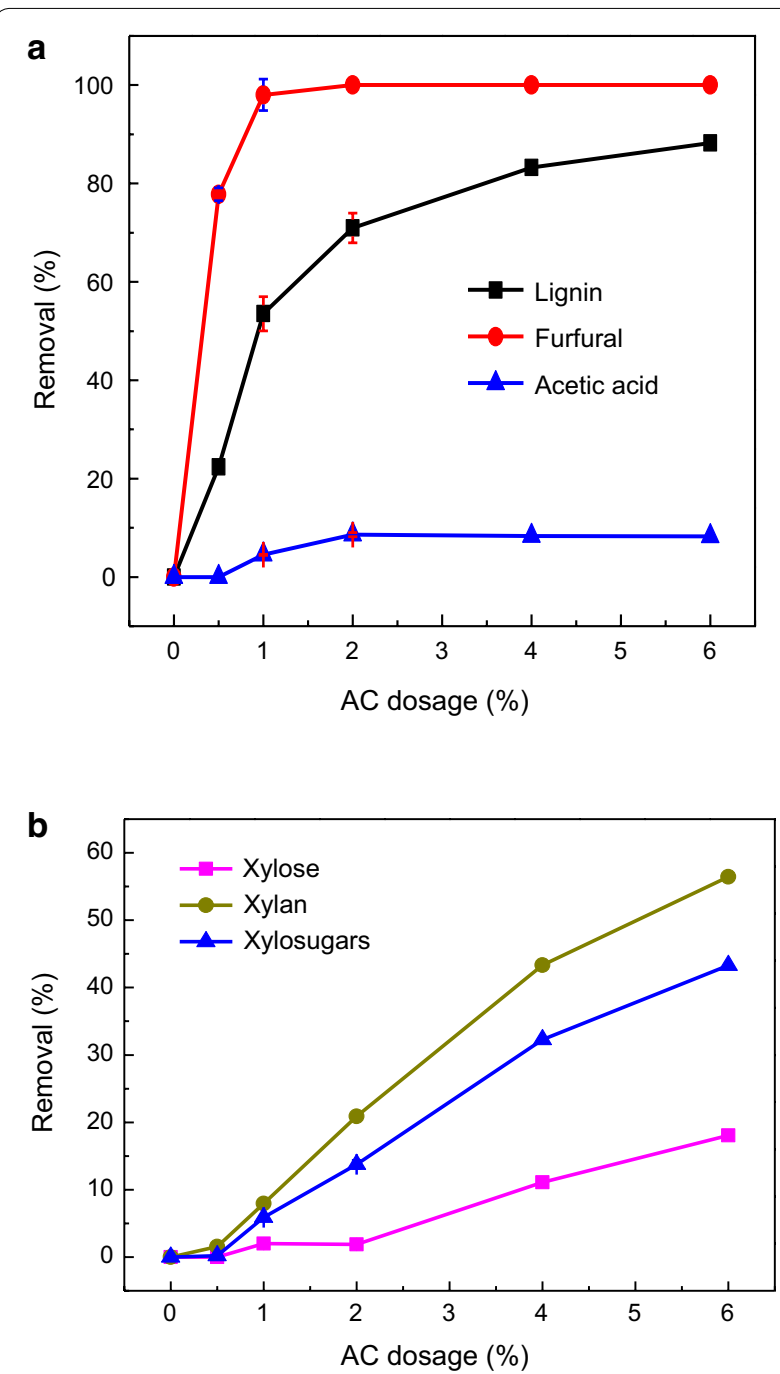

Fig. 4 Effect of AC dosage on the constituents of PHL-1st (a removal of lignin, furfural and acetic acid; $\mathbf{b}$ removal of xylose, xylan and xylosugars) 


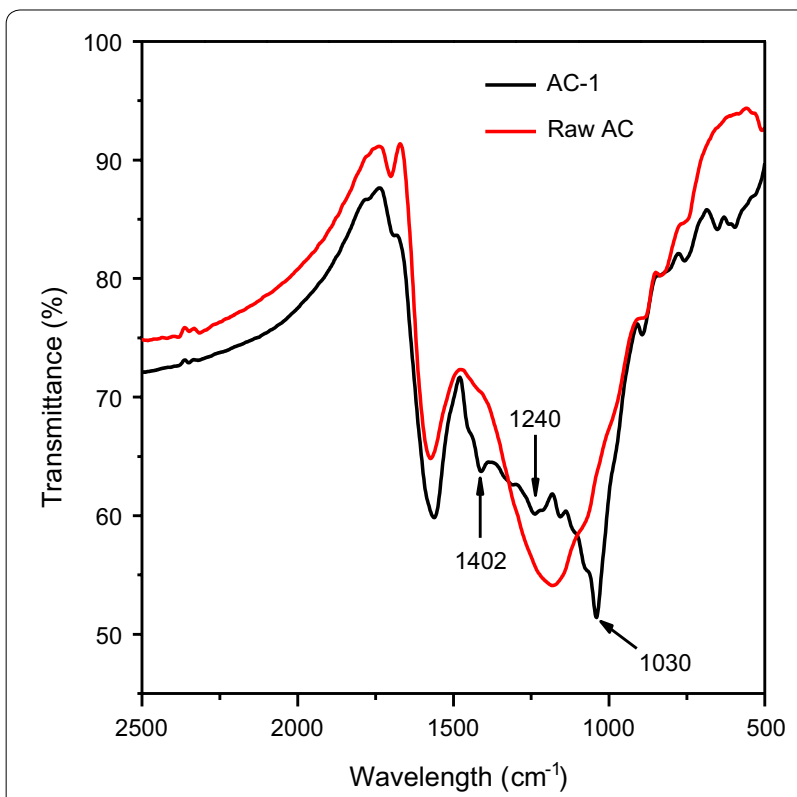

Fig. 5 FTIR spectrum of the untreated $A C$ and treated $A C-1$

Fig. 4a that the removal of lignin and furfural were 53.5\% and $98.0 \%$, respectively, at $1 \mathrm{wt} \%$ AC dosage. Further increase in the AC dosage had a slight effect on the contaminant removal. However, AC treatment had no effect on the removal of acetic acid.

Figure $4 \mathrm{~b}$ showed that the removal of xylosugars was significantly increased with the AC dosage increase, which is due to its higher adsorption on the AC surface. At a lower AC dosage ( $<1.0 \mathrm{wt} \%)$, there are only limited adsorption for lignin, furfural and xylosugars on activated carbon. Lignin and furfural are more hydrophobic than xylosugars, and thus they were easy to be removed by adsorption $[4,16]$. Almost all of lignin and furfural were removed at a higher dosage of $\mathrm{AC}$ at the expense of some xylosugar removals, which implied that the selectivity of AC adsorption decreased.

The removal of xylosugars was mainly attributed to their adsorption onto AC. As reported earlier, oligosugars have lower solubility and higher tendency for isolation from solutions [1]. It was well illustrated that xylan has higher value than xylose for pharmaceutical and food applications [29]. Hence the optimal AC dosage was selected as $1 \mathrm{wt} \%$ based on the minimum of xylan removal.

The treated $\mathrm{AC}-1$ and untreated $\mathrm{AC}$ were analyzed by FTIR, and the results are shown in Fig. 5. It can be seen that several peaks appeared after adsorbing organics on AC-1. The peak at $1420 \mathrm{~cm}^{-1}$ is ascribed to the carboxyl vibration of sodium carboxylate. The peaks at 1240 and $1030 \mathrm{~cm}^{-1}$ could be assigned to the $\mathrm{C}-\mathrm{H}$ and $\mathrm{C}-\mathrm{O}$ bending of guaiacyl ring [28]. FTIR spectrum illustrated that parts of lignin and lignin-derivatives were adsorbed onto $\mathrm{AC}$ in the $\mathrm{AC}$ adsorption process.

\section{Laccase assisted AC treatment}

The aim of laccase assisted AC treatment is to polymerize the low molecular weight lignin of PHL-2nd by laccase so that their adsorption on $\mathrm{AC}$ is improved. The optimal laccase dosage, $\mathrm{pH}$, treatment temperature and time were studied in the laccase treatment process, and the results are shown in Fig. 6 . As can be seen, the maximum lignin removal was obtained at a $5 \mathrm{U} / \mathrm{g}$ of laccase dosage and $\mathrm{pH} 5$, respectively (Fig. 6a). The laccase treatment was effective in a wide range of $\mathrm{pH}$ from 4.8 to 8 (Fig. 6b). The optimal temperature for laccase treatment was $45^{\circ} \mathrm{C}$ and a higher temperature reduced the lignin removal rate. The optimal reaction time for laccase treatment was $3 \mathrm{~h}$ (Fig. 6d), and an increase in the treatment time did not affect the lignin removal. Lignin polymerization reaction is a radical-radical coupling reaction that would start by the laccase oxidation of phenolic end groups [30]. Thus, laccase facilitated the polymerization of lignin and the subsequent isolation of polymerized lignin due to its low solubility [1]. The optimal conditions of laccase treatment were $5.0 \mathrm{U} / \mathrm{g}$ of laccase dosage, $\mathrm{pH} 5,45^{\circ} \mathrm{C}$ and $3 \mathrm{~h}$ based on the maximum lignin removal achieved in this process.

The molecular weight of lignin of the PHL treated and untreated by laccase were analyzed as listed in Table 2 . The molecular weight of lignin in PHL-2nd was too small to be determined, and thus is not reported. The results showed that the molecular weight $(\mathrm{Mw})$ of lignin obtained under optimized conditions was $127 \%$ larger than that before laccase treatment, which supported the conclusion that lignin grafting/coupling reactions were induced by laccase [24]. It can also be seen in Table 2 that a high temperature $\left(60^{\circ} \mathrm{C}\right)$ made laccase deactivated, confirming the results shown in Fig. 6c. In addition, by increasing the treatment time from 3 to $24 \mathrm{~h}$, the molecular weight of lignin increased slightly, the weight average molecular weight $(\mathrm{Mw})$ increased from 6218 to $7418 \mathrm{~g} /$ mol, while its number average molecular weight $(\mathrm{Mn})$ negligibly changed. The reason might be due to the fact that the molecular weight of lignin became sufficiently large in polymerization process that caused the steric hindrance for further extension of polymerization at a laccase treatment prolonged time [12].

PHL-3rd was obtained under the optimal laccase treatment conditions. PHL-3rd was treated in the 2nd stage of $\mathrm{AC}$ adsorption at different $\mathrm{AC}$ dosages, and the results are shown in Fig. 7. It can be seen that the removal of lignin, acetic acid and xylosugars from the PHL-3rd increased by $64 \%, 6 \%$ and $3 \%$, respectively, with increasing the AC dosage from 0 to $1 \mathrm{wt} \%$. However, with further 

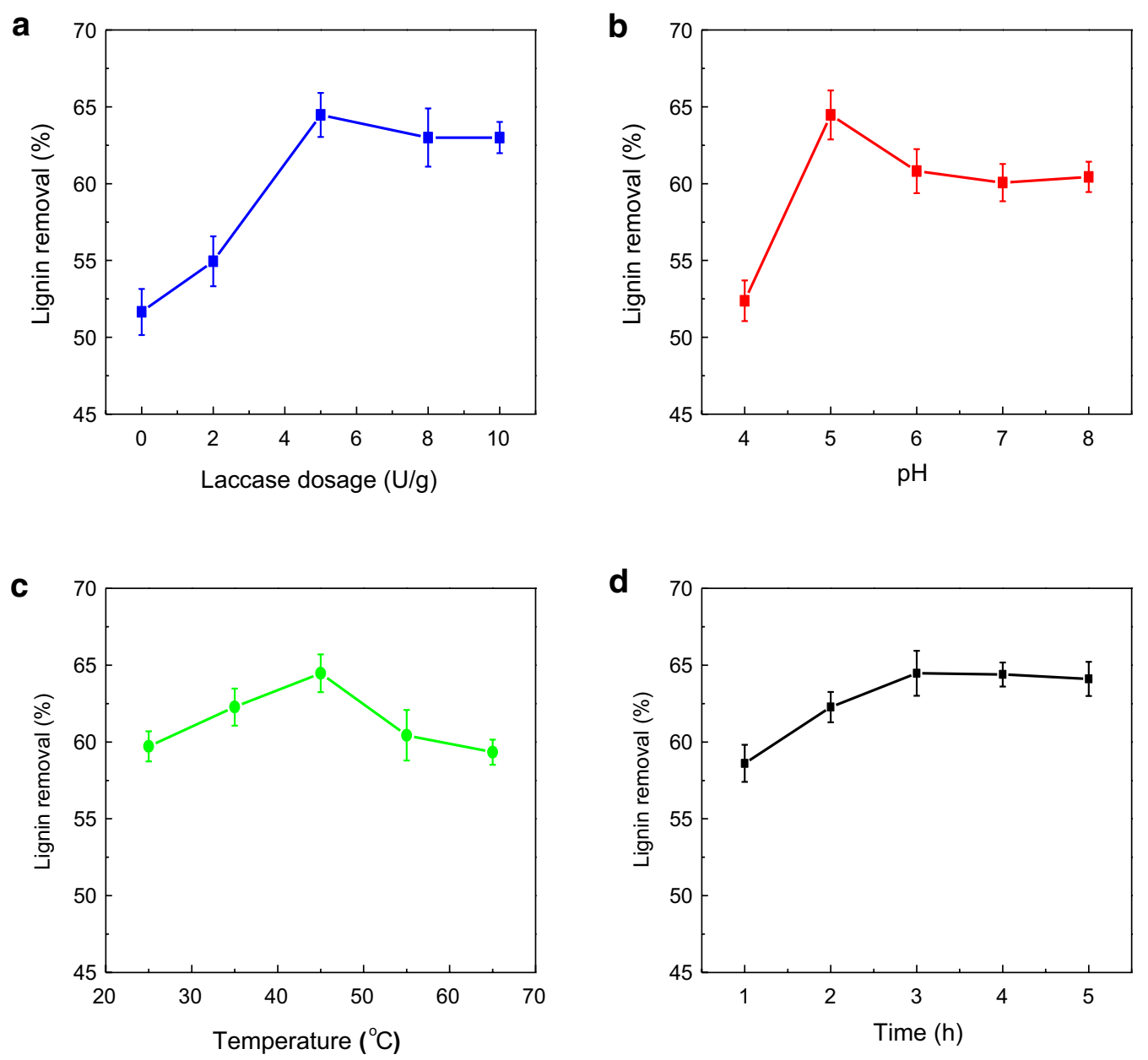

Fig. 6 Effect of laccase treatment on lignin removal of PHL-2nd. The other treating conditions: a pH 5, temperature $45^{\circ} \mathrm{C}$ and time $3 \mathrm{~h} ; \mathbf{b}$ laccase dosage $5 \mathrm{U} / \mathrm{g}$, temperature $45^{\circ} \mathrm{C}$ and time $3 \mathrm{~h}$; c laccase dosage $5 \mathrm{U} / \mathrm{g}, \mathrm{pH} 5$ and time $3 \mathrm{~h}$; $\mathbf{d}$ laccase dosage $5 \mathrm{U} / \mathrm{g}, \mathrm{pH} 5$ and temperature $45^{\circ} \mathrm{C}$

Table 2 Molecular weight of lignin in PHL treated and untreated with laccase

\begin{tabular}{llll}
\hline Lignin & Mn (g/mol) & Mw (g/mol) & Mw/Mn \\
\hline $\begin{array}{l}\text { Before laccase treatment in } \\
\text { PHL-2nd }\end{array}$ & 3065 & 4909 & 1.60 \\
$\begin{array}{l}\text { Laccase treated under optimized } \\
\text { conditions in PHL-3rd }\end{array}$ & 3705 & 6218 & 1.67 \\
$\begin{array}{l}\text { Laccase treated for } 24 \mathrm{~h} \text { in } \\
\quad \text { PHL-3rd }\end{array}$ & 3690 & 7418 & 2.01 \\
$\begin{array}{l}\text { Laccase treated at } 60{ }^{\circ} \mathrm{C} \text { in } \\
\quad \text { PHL-3rd }\end{array}$ & 3339 & 5518 & 1.65 \\
\hline
\end{tabular}

Mn number average molecular weight, $M w$ weight average molecular weight, $M n / M w$ polydispersity

increase in the AC dosage, the removal of lignin and acetic acid slightly decreased, while the xylosugars removal increased rapidly. Therefore, the optimal AC dosage was of $1.0 \mathrm{wt} \%$, resulting the maximum lignin removal and the minimum xylosugars removal from PHL.
The changes in the specific surface area and pore volume of the treated $\mathrm{AC}$ and the raw $\mathrm{AC}$ are listed in Table 3. The total specific surface area and pore volume of AC-2 and AC-3 decreased significantly compared to those of raw $\mathrm{AC}$ as lignin adsorbed on their surfaces and decreased their micropore surface and volume. However, the mesopore volume and its surface area changed slightly compared to micropore.

The hydrodynamic diameters of components in PHL3rd are listed in Table 4. It can be seen that the constituents of the PHL-3rd were in the size of $200-500 \mathrm{~nm}$. As a result, the constituents of the treated PHL influenced the pore characteristics of micropores of AC and its adsorbing efficiency. Therefore, their adsorption affected the pore characteristics of micropores, however, the amount of adsorbed components and the size of these components were such that they did not fully occupy all the space and area in the mesopores $[1,9]$. In addition, compared with $\mathrm{AC}-2$, the mesopore surface area and volume 

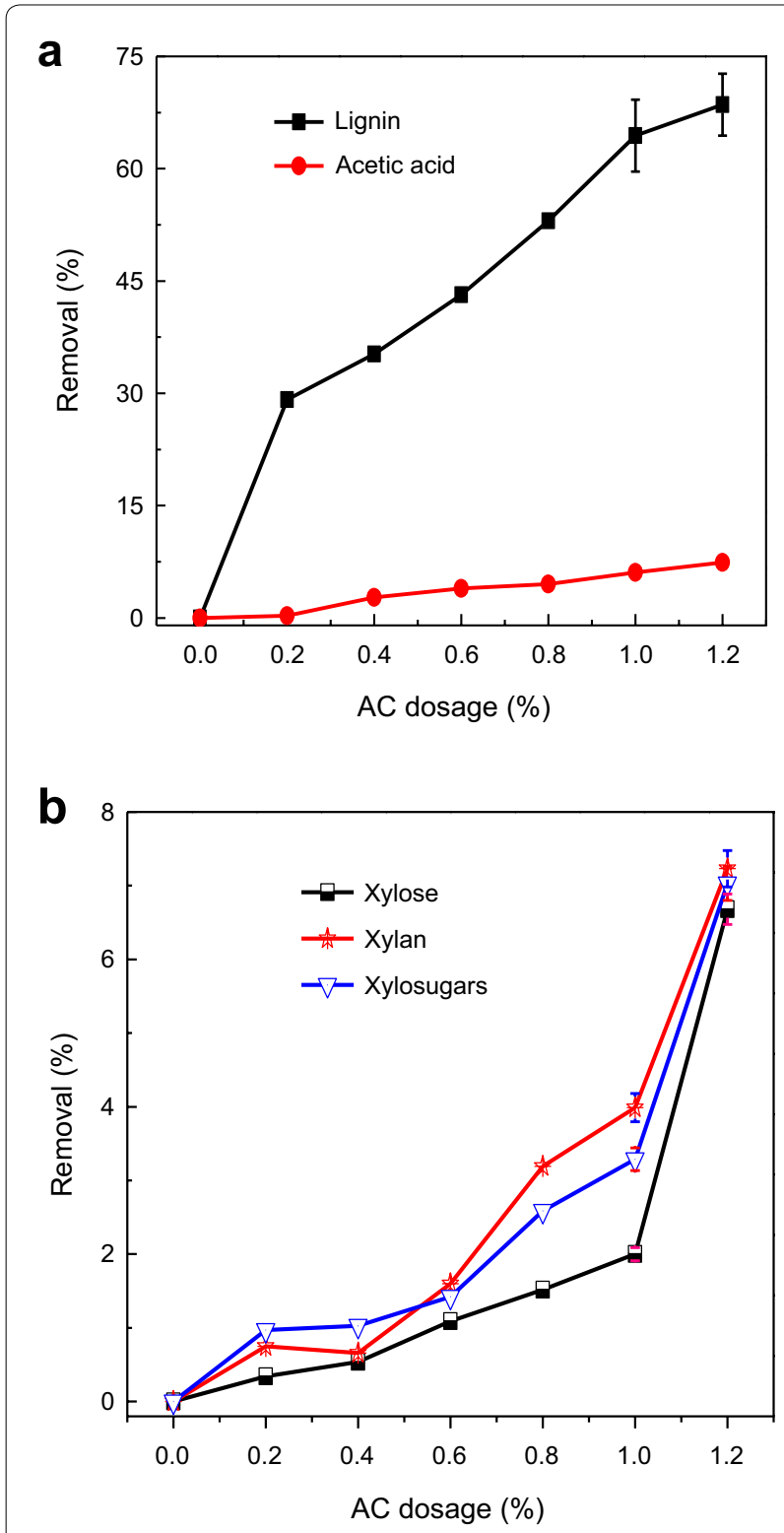

Fig. 7 Effect of AC dosage on the removal of lignin and acetic acid (a) and xylosugars (b) from PHL-3rd
Table 4 Hydrodynamic size of the components from different PHLs

Samples of PHL

Particle size (nm)

Origin PHL

342-825

PHL-1st

255-458

PHL-2nd

$255-342$

PHL-3rd

255-531

PHL-4th

$<21$

of AC-3 were reduced more dramatically. Therefore, laccase treatment made larger lignin polymers that they adsorbed on AC more effectively.

The hydrodynamic sizes of the components in the PHL obtained from different treating steps are shown in Table 4. The results showed that the particle size of PHL reduced after treating by $\mathrm{Ca}(\mathrm{OH})_{2}$ and 1 st $\mathrm{AC}$ adsorption stage. However, laccase treatment increased the particle size due to laccase-induced polymerization of lignin. The subsequent 2 nd $\mathrm{AC}$ adsorption stage treatment led to the removal of almost all lignin. Therefore, the particle size of components of PHL-4th was very small.

\section{Overall performance}

Table 5 shows the concentration of lignin, acetic acid, furfural and xylosugars at each treatment step. It can be seen that, after $\mathrm{Ca}(\mathrm{OH})_{2}$ treatment, the concentration of lignin and furfural of PHL decreased by $41.2 \%$ and $47.4 \%$, respectively. The concentration of xylose and xylan changed negligibly and the concentration of acetic acid increased twofolds, which showed the high selectivity of $\mathrm{Ca}(\mathrm{OH})_{2}$ treatment process. The 1st AC treatment and laccase assisted 2nd AC treatment were effective in removing lignin and furfural, but inefficient in removing acetic acid. Overall, the concentration of lignin decreased by $90.7 \%$ and furfural was entirely removed from PHL. Compared to the original

Table 3 Specific surface area and pore volume of ACs

\begin{tabular}{|c|c|c|c|c|c|c|}
\hline \multirow[t]{2}{*}{$\overline{A C}$} & \multicolumn{3}{|c|}{ Surface area $\left(\mathrm{m}^{2} / \mathrm{g}\right)$} & \multicolumn{3}{|c|}{ Pore volume $\left(\mathrm{cm}^{3} / \mathrm{g}\right)$} \\
\hline & $S_{\text {BET }}$ & $S_{\text {micr }}$ & $S_{\text {meso }}$ & $\overline{V_{\text {BET }}}$ & $V_{\text {micr }}$ & $V_{\text {meso }}$ \\
\hline Raw AC & 1185.4 & 707.7 & 435.5 & 1.1 & 0.3 & 0.7 \\
\hline$A C-2$ & 173.0 & 0 & 172.3 & 0.3 & 0 & 0.3 \\
\hline$A C-3$ & 107.4 & 0 & 105.7 & 0.2 & 0 & 0.2 \\
\hline
\end{tabular}

$A C-2$ precipitates obtained by treating $\mathrm{PHL}-2 \mathrm{nd}, A C-3$ precipitates obtained by treating $\mathrm{PHL}-3 \mathrm{rd}$ 
Table 5 Effect of different treating steps on the concentration of PHL components

\begin{tabular}{lllllll}
\hline PHL & Lignin (g/L) & Acetic acid (g/L) & HMF (g/L) & Xylose (g/L) & Xylan (g/L) & Xylosugars (g/L) \\
\hline Origin PHL & $9.7 \pm 0.49$ & $6.2 \pm 0.26$ & $1.9 \pm 0.1$ & $12.3 \pm 0.68$ & $23.3 \pm 0.79$ & $35.6 \pm 1.47$ \\
PHL-1st & $5.7 \pm 0.29$ & $11.7 \pm 0.59$ & $1.0 \pm 0.04$ & $12.1 \pm 0.56$ & $23.1 \pm 0.99$ & $35.2 \pm 1.55$ \\
PHL-2nd & $2.6 \pm 0.17$ & $11.2 \pm 0.34$ & 0.1 & $11.8 \pm 0.47$ & $21.3 \pm 0.89$ & $33.1 \pm 1.36$ \\
PHL-4th & $0.9 \pm 0.07$ & $12.7 \pm 0.55$ & 0 & $11.6 \pm 0.52$ & $20.5 \pm 0.98$ & $32.1 \pm 1.5$ \\
Removal (\%) & 90.7 & - & 100 & 5.7 & 12.0 & 9.9 \\
\hline
\end{tabular}

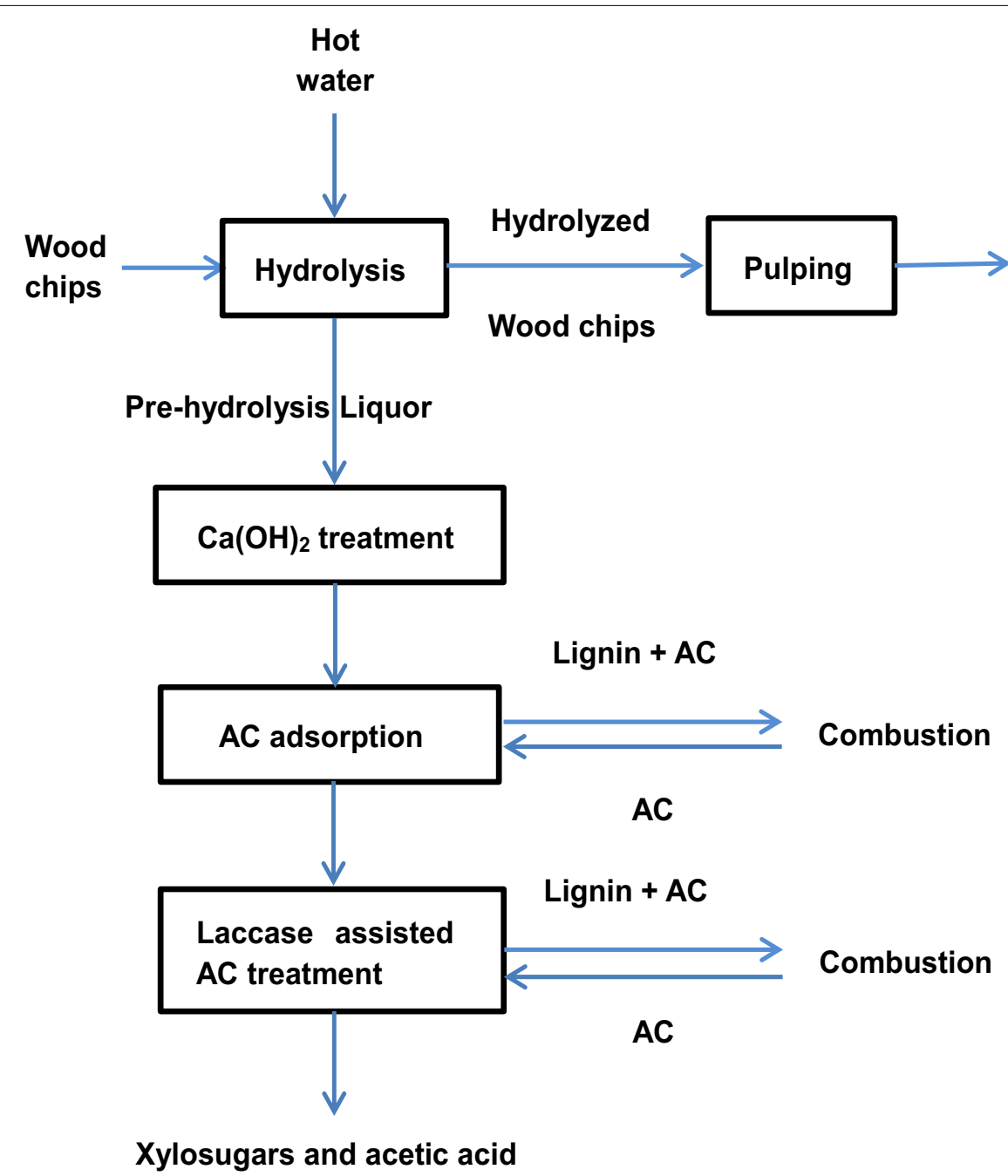

Fig. 8 Proposed process for contaminant removal of PHL and xylosugars and acetic acid production

PHL, the concentration of xylosugars decreased by $9.9 \%$ (12\% xylan and $5.7 \%$ xylose). In another work, the application of polydimethyl diallyl ammonium chloride (PDADMAC) led to $36.8 \%$ sugar removal and $70.3 \%$ lignin removal [14]. The PHL treatment of lime-resin resulted in 95\% lignin removal and $21.2 \%$ sugar removal [31]. Comparatively, the combination of $\mathrm{Ca}(\mathrm{OH})_{2}, \mathrm{AC}$ and laccase treatment process was more effective in this work.
Proposed process for lignin removal from PHL

Figure 8 shows a proposed process for contaminant removal from PHL and xylosugars production. This process includes $\mathrm{Ca}(\mathrm{OH})_{2}$ treatment, $\mathrm{AC}$ adsorption, laccase assisted AC treatment and xylosugar purification, which were proposed based on the results obtained in this work. There were two advantages for using $\mathrm{Ca}(\mathrm{OH})_{2}$ treatment in the first step: (1) pH adjustment of PHL and (2) contaminant removal. The 1st AC adsorption could 
Table 6 Analysis of elements and property of AC from the different treating steps

\begin{tabular}{lllllllll}
\hline Samples of AC & Ash (\%) & C (\%) & H (\%) & O (\%) & N (\%) & S (\%) & HHV (MJ/kg) & $\begin{array}{l}\text { Total HHV } \\
\text { for } \mathbf{~ k g ~ o f ~ A C ~} \\
\text { (MJ) }\end{array}$ \\
\hline Raw AC & 3.4 & 77.7 & 2.9 & 16.0 & 0.3 & 0.2 & 28.8 & 28.8 \\
AC-1 & 5.4 & 65.1 & 3.5 & 25.7 & 0.3 & 0.1 & 24.1 & 37.7 \\
AC-3 & 6.3 & 64.4 & 3.3 & 25.7 & 0.3 & 0.1 & 23.6 & 31.6 \\
\hline
\end{tabular}

further remove macromolecular lignin from the PHL that was already treated by $\mathrm{Ca}(\mathrm{OH})_{2}$ (i.e., from PHL-1st). Lignin would be effectively adsorbed on $\mathrm{AC}$, and the treated AC could be activated and recovered for reuse in a reactor via oxidation using different chemicals. The combination of laccase and 2nd AC treatment could help further remove the residual lignin and furfural from the PHL. The AC treated in the 2nd AC stage can be combined with that treated in the 1st AC stage to be activated and recovered for reusing. The laccase and lignin can be desorbed from AC, e.g., via steam or alkaline treatment $[32,33]$. The purified PHL with xylosugars and acetic acid could be used to produce value-added products, such as ethanol and xylitol $[34,35]$. The presence of acetic acid in PHL would help the production of xylose [36, 37].

Despite promising results, the order of process steps may be altered for better outcomes and the authors are currently working on this aspect. After optimizing the process, economic analysis should be conducted to validate the feasibility of the developed process.

Analysis of elements and property of AC from the different treating steps are shown in Table 6. It can be seen that the high heating value (HHV) of the treated $\mathrm{AC}$ increased due to the extra thermal energy from burning lignin and other components adsorbed onto AC. The adsorption of lignocelluloses increased the overall mass of the AC-based product and the elemental compositions of the treated AC changed compared to those of the untreated AC. In addition, the adsorbed lignocelluloses may have different structures, which may be another reason for different HHV of the treated AC [3].

Although the results showed promising contaminant removals and a strategy for energy recovery, the impact of the process on down steam fermentation processes for conversion of xylosugars to value-added products has not been examined in this work. Also, economic analysis and feasibility studies need to be conducted to determine the overall profitability of the proposed process.

\section{Conclusions}

A novel process for separating contaminants from PHL was attested experimentally at a lab scale. $\mathrm{Ca}(\mathrm{OH})_{2}$ treatment was effective in selectively removing lignin and furfural from PHL without influencing the concentration of xylosugars. The 1st AC adsorption could remove lignin and furfural effectively and was ineffective in removing acetic acid. Xylan was more adsorbed on AC than xylose. Interestingly, the in situ system of laccase and AC improved the removal of contaminants by $17.6 \%$, and this improvement was originated from the polymerization tendency of laccase for lignin. Overall, the removal rates of lignin, furfural and xylosugars were $90.4 \%, 100 \%$ and $9.9 \%$, respectively. Based on the results, a new process was proposed for purifying PHL for downstream sugar-based biorefineries and generating heat that can be potentially used in the proposed process.

\section{Authors' contributions \\ $J C$ was the main author of this work. MH, JD and FX conducted laboratory experiments for this work. GY was the lead supervisor of the group on this project and PF provided an overall assessment of this work. All authors read and approved the final manuscript.}

\section{Authors' information}

Dr. Jiachuan Chen is a professor and Vice-chairman of China Technical Association of Paper Industry. He has been working on the extraction, separation and purification of celluloses, hemicelluloses and lignin from wood, straws and pulping spent liquors. He has also been working on the preparation of bioproducts and functional materials.

Jiran Dong is a full-time graduate student. She has been working on the separation and purification of hemicelluloses from pre-hydrolysis liquor. She has also been working on the preparation of functional xylooligosaccharide.

Guihua Yang is a professor, Experts of State Council Special Allowance and Taishan Scholar. She has been working on the separation and purification of celluloses, hemicelluloses and lignin from various fiber resources and pulping spent liquors. She has also been working on the environmentally friendly technologies for the production of high yield pulp and on the preparation of functional materials.

Feng $\mathrm{Xu}$ is a full-time graduate student. He has been working on the separation and purification of hemicelluloses from pre-hydrolysis liquor.

Dr. Ming He is working on the production and application of nanocellulose-based functional materials for various fiber products. He is currently a full-time lecturer at Qilu University of Technology.

Dr. Pedram Fatehi is an associate professor, Canada Research Chair (Tier II) and Industrial Research Chair of Chemical Engineering Department at Lakehead University, Canada. He has been working on the production of value-added materials from lignin and hemicellulose.

\section{Author details}

${ }^{1}$ State Key Laboratory of Bio-based Materials and Green Papermaking, Qilu University of Technology (Shandong Academy of Sciences), Jinan 250353, Shandong, China. ${ }^{2}$ Green Processes Research Centre and Department of Chemical Engineering, Lakehead University, Thunder Bay, ON P7B 5E1, Canada. 


\section{Competing interests}

The authors declare that they have no competing interests.

\section{Availability of supporting data}

Not applicable.

\section{Consent for publication}

Not applicable.

Ethics approval and consent to participate

Not applicable.

\section{Funding and acknowledgements}

The authors are grateful for the financial supports received from the National Key R\&D Program of China (2017YFB0307900), National Natural Science Foundation of China (Grant No. 31670595, 31770628) and the Taishan Scholars Program.

\section{Publisher's Note}

Springer Nature remains neutral with regard to jurisdictional claims in published maps and institutional affiliations.

Received: 4 September 2018 Accepted: 10 December 2018

Published online: 21 December 2018

\section{References}

1. Fatehi P, Ryan J, Ni Y. Adsorption of lignocelluloses of model pre-hydrolysis liquor on activated carbon. Bioresour Technol. 2013;131:308-14.

2. Saeed A, Fatehi P, Ni Y. Chitosan as a flocculant for pre-hydrolysis liquor of kraft-based dissolving pulp production process. Carbohydr Polym. 2011:86:1630-6.

3. Shen J, Fatehi P, Soleimani P, Ni Y. Recovery of lignocelluloses from prehydrolysis liquor in the lime kiln of kraft-based dissolving pulp production process by adsorption to lime mud. Bioresour Technol. 2011;102:10035-9.

4. Fatehi $P_{1}$ Chen J. Extraction of technical lignins from pulping spent liquors, challenges and opportunities. In: Zhen F, Richard L, editors. Production of biofuels and chemicals from lignin. Singapore: Springer; 2016. p. 35-54

5. Cipriani TR, Mellinger CG, de Souza LM, Baggio CH, Freitas CS, Marques MC, Gorin PA, Sassaki GL, lacomini M. A polysaccharide from a tea (infusion) of Maytenus ilicifolia leaves with anti-ulcer protective effects. J Nat Prod. 2006;69:1018-21.

6. Kardosova A, Malovikova A, Patoprsty V, Nosal'Ova G, Matakova T. Structural characterization and antitussive activity of a glucuronoxylan from Mahonia aquifolium (Pursh) Nutt. Carbohydr Polym. 2002:47:27-33.

7. Kulicke WM, Thielking $\mathrm{H}$, Lettau Al. Correlation between immunological activity, molarmass, and molecular structure of different (1-3)-BETA-D-glucans. Carbohydr Res. 1997;297:135

8. Lee HJ, Lim WS, Lee JW. Improvement of ethanol fermentation from lignocellulosic hydrolysates by the removal of inhibitors. J Ind Eng Chem. 2013;19:2010-5

9. Liu X, Fatehi P, Ni Y. Adsorption of lignocelluloses dissolved in prehydrolysis liquor of kraft-based dissolving pulp process on oxidized activated carbons. Ind Eng Chem Res. 2011;50:11706-11.

10. García A, Toledano A, Serrano L, Egüés I, González M, Marín F, Labidi J. Characterization of lignins obtained by selective precipitation. Sep Purif Technol. 2009;68:193-8.

11. Blanc C-L, Lemaire J, Duval F, Théoleyre M-A, Pareau D. Purification of pentoses from hemicellulosic hydrolysates without neutralization for sulfuric acid recovery. Sep Purif Technol. 2017;174:513-9.

12. Gouveia S, Fernández-Costas C, Sanromán MA, Moldes D. Polymerisation of Kraft lignin from black liquors by laccase from Myceliophthora thermophila: effect of operational conditions and black liquor origin Bioresour Technol. 2013;131:288-94

13. González Alriols M, García A, Llanoponte R, Labidi J Combined organosolv and ultrafiltration lignocellulosic biorefinery process. Chem Eng J. 2010:157:113-20

14. Yasarla LR, Ramarao BV. Dynamics of flocculation of lignocellulosic hydrolyzates by polymers. Ind Eng Chem Res. 2012;51:6847-61.
15. Shen J, Fatehi P, Soleimani P, Ni Y. Lime treatment of prehydrolysis liquor from the kraft-based dissolving pulp production process. Ind Eng Chem Res. 2011:51:662-7.

16. Shen J, Kaur I, Baktash MM, He Z, Ni Y. A combined process of activated carbon adsorption, ion exchange resin treatment and membrane concentration for recovery of dissolved organics in pre-hydrolysis liquor of the kraft-based dissolving pulp production process. Bioresour Technol. 2013;127:59-65.

17. Lee JM, Venditti RA, Jameel H, Kenealy WR. Detoxification of woody hydrolyzates with activated carbon for bioconversion to ethanol by the thermophilic anaerobic bacterium Thermoanaerobacterium saccharolyticum. Biomass Bioenergy. 2011;35:626-36.

18. Qiang W, Liu S, Yang G, Chen J. Modeling laccase-induced lignin removal in prehydrolysis liquor from kraft-based dissolving pulp production. Bioresour Technol. 2015;175:638-41.

19. Mansfield SD. Laccase impregnation during mechanical pulp processing: improved refining efficiency and sheet strength. Appita J. 2002;55:49-53.

20. Huo D, Fang G, Yang Q, Han S, Deng Y, Shen K, Lin Y. Enhancement of eucalypt chips'enzymolysis efficiency by a combination method of alkali impregnation and refining pretreatment. Bioresour Technol. 2013:150:73-8.

21. Fatehi P, Kititerakun R, Ni Y, Xiao H. Synergy of CMC and modified chitosan on strength properties of cellulosic fiber network. Carbohydr Polym. 2010;80:208-14.

22. Ni Y, Jahan MS, Yang G. Structural characterization of pre-hydrolysis liquor lignin and its comparison with other technical lignins. Curr Org Chem. 2013;17:1589-95

23. Channiwala SA, Parikh PP. A unified correlation for estimating HHV of solid, liquid and gaseous fuels. Fuel. 2002;81:1051-63.

24. Wang Q, Jahan MS, Liu S, Miao Q, Ni Y. Lignin removal enhancement from prehydrolysis liquor of kraft-based dissolving pulp production by laccaseinduced polymerization. Bioresour Technol. 2014;164:380-5.

25. Mohagheghi A, Ruth M, Schell DJ. Conditioning hemicellulose hydrolysates for fermentation: effects of overliming $\mathrm{pH}$ on sugar and ethanol yields. Process Biochem. 2006;41:1806-11.

26. Konduri MK, Kong F, Fatehi P. Production of carboxymethylated lignin and its application as a dispersant. Eur Polym J. 2015;70:371-83.

27. And SK, Kadla JF. Hydrogen bonding in lignin: a Fourier transform infrared model compound study. Biomacromolecules. 2005;6:2815-21.

28. Liu Z, Fatehi P, Jahan MS, Ni Y. Separation of lignocellulosic materials by combined processes of pre-hydrolysis and ethanol extraction. Bioresour Technol. 2011;102:1264-9.

29. Watson K, Gooderham NJ, Davies DS, Edwards RJ. Interaction of the transactivating protein HIV-1 tat with sulphated polysaccharides. Biochem Pharmacol. 1999:57:775-83.

30. Sangha AK, Parks JM, Standaert RF, Ziebell A, Davis M, Smith JC. Radical coupling reactions in lignin synthesis: a density functional theory study. J Phys Chem B. 2012;116:4760-8.

31. Wang Z, Jiang J, Wang X, Fu Y, Li Z, Zhang F, Qin M. Selective removal of phenolic lignin derivatives enables sugars recovery from wood prehydrolysis liquor with remarkable yield. Bioresour Technol. 2014;174:198-203.

32. Gu J, Bart HJ. Heat and mass transfer in steam desorption of an activated carbon adsorber. Int Commun Heat Mass. 2005:32:296-304.

33. Vences-Alvarez E, Razo-Flores E, Lázaro I, Briones-Gallardo R, Velasco-Martínez G, Rangel-Mendez R. Gold recovery from very dilute solutions from a mine in closing process: adsorption-desorption onto carbon materials. J Mol Liq. 2017;240:549-55.

34. Ahsan $L$, Jahan MS, Ni Y. Recovering/concentrating of hemicellulosic sugars and acetic acid by nanofiltration and reverse osmosis from prehydrolysis liquor of kraft based hardwood dissolving pulp process. Bioresour Technol. 2014;155:111-5.

35. Yang G, Jahan MS, Ahsan L, Zheng L, Ni Y. Recovery of acetic acid from pre-hydrolysis liquor of hardwood kraft-based dissolving pulp production process by reactive extraction with triisooctylamine. Bioresour Technol. 2013;138:253-8.

36. Zhang H, Xu Y, Yu S. Co-production of functional xylooligosaccharides and fermentable sugars from corncob with effective acetic acid prehydrolysis. Bioresour Technol. 2017:234:343-9.

37. Zhang H, Zhou X, Xu Y, Yu S. Production of xylooligosaccharides from waste xylan, obtained from viscose fiber processing, by selective hydrolysis using concentrated acetic acid. J Wood Chem Technol. 2017;37:1-9. 